\title{
PRODUÇÃO DE QUEIJO TIPO QUARK FUNCIONAL CONTENDO EXOPOLISSACARÍDEOS
}

\section{Production of functional Quark cheese containing exopolysaccharides}

\author{
Tatia Tie Yuhara ${ }^{1}$, Suzana Tiemi Matsubara ${ }^{1}$, Joice Sifuentes dos Santos ${ }^{2}$, Sandra Garcia ${ }^{1 *}$
}

\section{RESUMO}

Alimentos com bactérias probióticas ou prebióticos estão incluídos na categoria de alimentos contendo compostos bioativos que tem despertado interesse devido ao efeito benéfico sobre a saúde. O objetivo do trabalho foi a formulação de produto simbiótico e funcional com bactérias láticas probióticas produtoras de exopolissacarídeos (EPS). Para isto, promoveu-se a fermentação por 24 h a $37{ }^{\circ} \mathrm{C}$ de soro de leite em pó e leite desnatado em duas formulações: " $F$ " contendo o prebiótico goma acácia e inoculada de bactéria probiótica Lactobacillus casei LC1, e " $F_{2}$ " formulada com inulina como prebiótico e fermentação por L. acidophilus LA5. Nos produtos fermentados foi determinada a quantidade de EPS produzida pelos diferentes probióticos e os valores encontrados foram de $103,5 \mathrm{mg} / 100 \mathrm{~g}$ $\left(\mathrm{F}_{1}\right)$ e $109,2 \mathrm{mg} / 100 \mathrm{~g}\left(\mathrm{~F}_{2}\right)$. Verificou-se que os produtos apresentaram estabilidade microbiológica e físico-química com contagens de probióticos ao final de 21 dias de armazenamento refrigerado de $2,5 \times 10^{9} \mathrm{UFC} / \mathrm{g}, \mathrm{pH} 3,98$ e $32 \%$ de extrato seco total (EST) para $\mathrm{F}_{1}$ e $6,0 \times 10^{8} \mathrm{UFC} / \mathrm{g}, \mathrm{pH} 4,16$ e $31,5 \%$ EST para $\mathrm{F}_{2}$, ausência $S$. aureus e de coliformes. Conclui-se que o queijo Quark funcional apresentou altas contagens de bactérias láticas probióticas e presença de EPS, níveis estes importantes para a ação como alimentos funcionais e sobrevivência no trato gastrointestinal.

Palavras-chave: Quark; lactobacilos; goma acácia; frutanos.
ABSTRACT
Food that contain probiotic bacteria and prebiotics are included in the
1 Universidade Estadual de Londrina (UEL), Rodovia Celso Garcia Cid, PR 445 km 380, Campus Universitário, 86051-990, Londrina, PR, Brasil. E-mail: sgarcial@uel.br
2 Universidade Norte do Paraná (UNOPAR), R. Marselha, 591, Jardim Piza, 86041-140, Londrina, PR, Brasil.
* Autor para correspondência. 
functional food category that has gain interest due to the beneficial effect on health. The aim of this work was the formulation of a symbiotic and functional product, with high viability of probiotic lactic acid bacteria which are exopolyssacharides (EPS) producers. It was promoted the whey and reconstituted skim milk powder fermentation for $24 \mathrm{~h}$ at $37{ }^{\circ} \mathrm{C}$ in two formulations: " $\mathrm{F}_{1}$ " containing acacia gum as prebiotic and inoculated with probiotic bacteria Lactobacillus casei LC1, and " $\mathrm{F}_{2}$ " containing inuline as prebiotic and fermented with L. acidophilus LA5. After fermentation, EPS determination was conducted, and values of $103.5 \mathrm{mg} / 100 \mathrm{~g}\left(\mathrm{~F}_{1}\right)$ and $109.2 \mathrm{mg} / 100 \mathrm{~g}\left(\mathrm{~F}_{2}\right)$ were obtained. It was verified that the products presented microbiological, physical and chemical stability and after 21 days of storage $\mathrm{F}_{1}$ presented probiotic bacteria counts of $2.5 \times 10^{9} \mathrm{CFU} / \mathrm{g}, \mathrm{pH} 3.98$ and total solids (TS) of $32 \% ; \mathrm{F}_{2}$ presented probiotic bacteria counts of $6.0 \times 10^{8} \mathrm{CFU} / \mathrm{g}, \mathrm{pH} 4.16$ and TS of $31.5 \%$. Coliforms and $S$. aureus were absent in the two formulations. It was concluded that the functional Quark cheese presented high counts of probiotic bacteria and EPS occurrence, levels which are important to the action as functional foods and survival in the gastrointestinal tract.

Keywords: Quark; Lactobacillus; acacia gum; frutans.

\section{INTRODUÇÃO}

A utilização de alegações de saúde na comercialização de produtos alimentícios como estratégia de marketing teve início nos anos 1960. Nos anos 1970, o direcionamento foi remover ou reduzir componentes não saudáveis tais como sal, açúcar ou gordura. A tendência continuou nos anos 1980 e finalmente, nos anos 1990, componentes mais saudáveis como vitaminas, antioxidantes, fibras e bactérias láticas probióticas foram adicionados aos alimentos (ZIEMER; GIBSON, 1998).

Dentro da categoria de alimentos e ingredientes funcionais encontram-se os alimentos com bactérias probióticas (fermentados ou não) e substratos específicos para essas bactérias consideradas benéficas, os prebióticos. Espécies de Lactobacillus spp. e de Bifidobacterium spp. têm sido empregadas como probióticas (ZIEMER; GIBSON, 1998). Substâncias como inulina, oligofrutose, goma acácia, amido resistente, isomalto-oligossacarídeos e $\beta$-glucana tem sido adicionadas aos alimentos devido às suas funções prebióticas (ROBERFROID, 1999; ZIEMER; GIBSON, 1998).

A Resolução RDC no 2/2002 define probióticos como microrganismos vivos capazes de melhorar o equilíbrio microbiano intestinal produzindo efeitos benéficos à saúde do indivíduo (ANVISA, 2002).

Várias funções benéficas dos probióticos têm sido descritas e incluem: 1. restabelecimento da microbiota intestinal balanceada; 2. resistência à colonização e/ou prevenção de diarreia; 3. redução sistêmica do colesterol sérico, redução de enzimas fecais e mutagênicos potenciais que possam induzir tumores; 4. metabolismo da lactose e redução da intolerância à lactose; 5. melhora na resposta do sistema imune; 6. melhor absorção de cálcio e 7 . síntese de vitaminas e pré-digestão de proteínas (ZIEMER; GIBSON, 1998).

Os exopolissacarídeos (EPS) microbianos são polissacarídeos ligados às células ou excretados como polissacarídeos livres e tem a função de proteção em ambientes naturais contra a fagocitose, ação de antibióticos ou condições adversas, como por exemplo, 
estresse osmótico. Possuem também papel no reconhecimento celular, na adesão a superfícies e na formação de biofilmes, facilitando a colonização em diferentes ecossistemas (RUAS-MADIEDO et al., 2001). Os EPS de bactérias láticas têm sido ainda pouco explorados como aditivos naturais ou funcionais por indústrias de alimentos. A inclusão desses compostos teria um impacto importante no desenvolvimento de novos produtos, fermentados ou não, com melhora nas propriedades reológicas, de textura, estabilidade e capacidade de retenção de água, em adição à estimulação do sistema imune (DE VUYST et al., 2001).

O queijo tipo Quark é o produto obtido a partir da fermentação e dessora de leite integral ou desnatado. Faz parte do grupo de queijos de massa fresca, que consiste de produtos lácteos acidificados, não maturados, consumidos logo após a fabricação e conservados obrigatoriamente sob refrigeração (SCHULZ-COLLINS; SENGE, 2004). É um queijo originário da Alemanha, podendo ser utilizado como queijo cremoso ou na culinária em geral. Na Europa, onde possui grande importância comercial e fabricado com tecnologia avançada, o queijo Quark e similares como o Petit-suisse, além de consumidos ao natural, são comercializados em vários sabores com adição de frutas ou de misturas balanceadas de condimentos. Também pode ser transformado em um produto aerado pela mistura com creme de leite batido, açúcar, aromatizantes e estabilizantes. O crescimento ou a incorporação de culturas probióticas ao queijo Quark já resfriado tem sido citada como uma alternativa interessante devido à lenta passagem deste produto pelo intestino, contribuindo, assim, para o processo de colonização.

O objetivo do presente trabalho foi elaborar queijo tipo Quark fermentado por microrganismos probióticos em duas diferentes formulações e avaliar a composição centesimal, a estabilidade microbiológicae a viabilidade dos probióticos durante o armazenamento refrigerado.

\section{MATERIAL E MÉTODOS}

Foram utilizadas como culturas probióticas as bactérias comerciais Lactobacillus acidophilus LA5 e Lactobacillus casei LC1, ambas da Christian Hansen. As linhagens liofilizadas foram reativadas em leite em pó desnatado reconstituído a $10 \%$ e incubadas a $37^{\circ} \mathrm{C}$, por $24 \mathrm{~h}$. Em seguida, foram repicadas na proporção de $1 \%(\mathrm{v} / \mathrm{v})$, incubadas sob as mesmas condições e armazenadas sob refrigeração para serem utilizadas posteriormente como inóculo.

\section{Cultivo dos microrganismos para produção de exopolissacarídeos}

O crescimento dos microrganismos probióticos foi realizado utilizando soro de leite em pó reconstituído a $7 \%(\mathrm{~m} / \mathrm{v})$ adicionado de $10 \%(\mathrm{~m} / \mathrm{v})$ leite desnatado. A cada uma das formulações foi adicionado goma acácia ou inulina na proporção de $0,5 \%(\mathrm{~m} / \mathrm{v})$, dependendo do probiótico.

\section{Processamento do queijo tipo Quark}

Soro de leite, leite em pó desnatado e prebióticos foram submetidos a tratamento térmico em banho de água a $85{ }^{\circ} \mathrm{C}$ durante $15 \mathrm{~min}$. Os prebióticos utilizados foram goma acácia (Fibre Gum ${ }^{\circledR}$ ), para a formulação inoculada com L. casei LC1 - Formulação "F "; e inulina (Raftiline ${ }^{\circledR}$ ), para a formulação inoculada com L. acidophilus LA5 Formulação " $\mathrm{F}_{2}$ ". Após o tratamento térmico e resfriamento a $37{ }^{\circ} \mathrm{C}, 1 \%$ de bactérias probióticas foram inoculadas e as formulações incubadas a $37^{\circ} \mathrm{C}$ por $24 \mathrm{~h}$. Após esse período, a dessora da massa foi realizada por $12 \mathrm{~h}$ sob refrigeração, utilizando-se tecido de 
algodão fino esterilizado (CHAMPAGNE et al., 1992). Os demais ingredientes (frutose $4 \%(\mathrm{~m} / \mathrm{m})$, sacarose $8 \%(\mathrm{~m} / \mathrm{m})$ e amido modificado H-50 BN 2\% (m/m)), comuns às duas formulações, foram adicionados à massa base e homogeneizados. O queijo Quark funcional obtido foi embalado e armazenado sob refrigeração a $4{ }^{\circ} \mathrm{C}$.

\section{Análises físico-químicas}

As determinações de $\mathrm{pH}$ dos queijos foram realizadas em potenciômetro digital, previamente calibrado. A determinação da atividade de água foi realizada utilizando o aparelho Aqualab (modelo CX-2) calibrado com água destilada. A composição centesimal do produto e a acidez titulável (expressa em \% de ácido lático) foram determinadas segundo a metodologia do Laboratório Nacional de Referência Animal (BRASIL, 1981). Todas as análises foram realizadas em duplicata.

\section{Quantificação de exopolissacarídeos}

A quantificação de exopolissacarídeos (EPS) nos meios após as fermentações foi realizada conforme descrito por SchiavãoSouza et al. (2007), em duplicata. Os valores encontrados para EPS foram calculados pela subtração da quantidade de polissacarídeos presentes no meio não inoculado (controle).

\section{Análises microbiológicas}

A contagem de L. casei LC1 e L. acidophilus LA5 presentes nos queijos Quark foi realizada no início e em intervalos regulares durante o armazenamento das diferentes formulações a $6{ }^{\circ} \mathrm{C}$. Alíquotas das diluições seriadas foram inoculadas, em duplicata, em ágar MRS e as placas incubadas a $37{ }^{\circ} \mathrm{C}$ por 48h (BRASIL, 1981). Os resultados foram expressos em unidades formadoras de colônias (UFC/g).
Os produtos foram avaliados microbiologicamente por meio das análises de coliformes totais, coliformes termotolerantes e Staphylococcus aureus conforme Brasil (1981). Os resultados foram expressos em UFC/g.

\section{Análise estatística}

Os parâmetros avaliados das duas formulações foram avaliadas em quatro tempos (1, 7, 14 e 21 dias) com 3 repetições. Os resultados foram analisados estatisticamente pela análise de variância e o teste t de Student a 5\% de significância, através do programa Statistica 7.0.

\section{RESULTADOS E DISCUSSÃO}

A crescente demanda pelos consumidores por produtos que aliam sabor e propriedades funcionais impulsiona o mercado de laticínios ao desenvolvimento de novos produtos. No presente trabalho, queijo tipo Quark fermentado por Lactobaccilus casei $\mathrm{LC} 1$ ou $L$. acidophillus LA5, adicionado de prebióticos goma acácia ou inulina para produção de exopolissacarídeos foi desenvolvido. As formulações apresentaram como diferencial a presença de polissacarídeos, que atuam contribuindo na formação de agregados celulares bacterianos e no reconhecimento e adesão a superfícies, facilitando a colonização em vários ecossistemas (ALP; ASLIM, 2010) e aumento da resistência ao estresse.

A Figura 1 apresenta os resultados de $\mathrm{pH}$, acidez titulável e viabilidade das bactérias probióticas L. casei LC1 e L. acidophilus LA5 durante o armazenamento dos queijos a $6{ }^{\circ} \mathrm{C}$. Observou-se que os valores médios de $\mathrm{pH}$ diminuíram nas duas formulações. Os valores de $\mathrm{pH}$ do queijo tipo Quark fermentado por L. casei LC1 variaram de 4,33 a 3,98 durante os 21 dias de armazenamento sob refrigeração de $6{ }^{\circ} \mathrm{C}$ e não diferiram estatisticamente $(\mathrm{p}>0,05)$. $\mathrm{O} \mathrm{pH}$ do produto 
formulado e fermentado por L. acidophilus LA5 apresentou valores médios de 4,26 a 4,16 durante o mesmo período de armazenamento sob as mesmas condições. Al-Kadamany et al. (2003) verificaram valores de $\mathrm{pH}$ inferiores ao presente trabalho em Labneh $(\mathrm{pH}=4,05)$, produto lácteo produzido por uma mistura de leite desnatado com creme de leite. Maruyama et al. (2006) também observaram diminuição do pH ao longo do armazenamento, com valores entre 4,7 e 4,4 ao longo de 21 dias de armazenamento de queijos Petit-suisse. Schulz-Collins; Senge (2004) citam valores médios de pH para Quark desnatado de 4,6.

Com relação à acidez titulável (Figura 1), pode-se observar aumento neste parâme- tro ao longo do período de armazenamento das duas formulações de queijo tipo Quark. A acidez do queijo formulado a partir do $L$. casei LC1 aumentou 26,5\% durante os 21 dias de armazenamento. Já a acidez do queijo formulado com L. acidophilus LA5 apresentou menor aumento, da ordem de $9,4 \%$ ao longo dos 21 dias de armazenamento.

A população de microrganismos probióticos (Figura 1) aumentou durante a primeira semana de armazenamento para a formulação $\mathrm{F}_{1}$ (L. casei LC1), seguida por gradual diminuição até o período final de estocagem (21 dias). A contagem de microrganismos probióticos na formulação $\mathrm{F}_{2}(L$. acidophilus LA5) apresentou diminuição
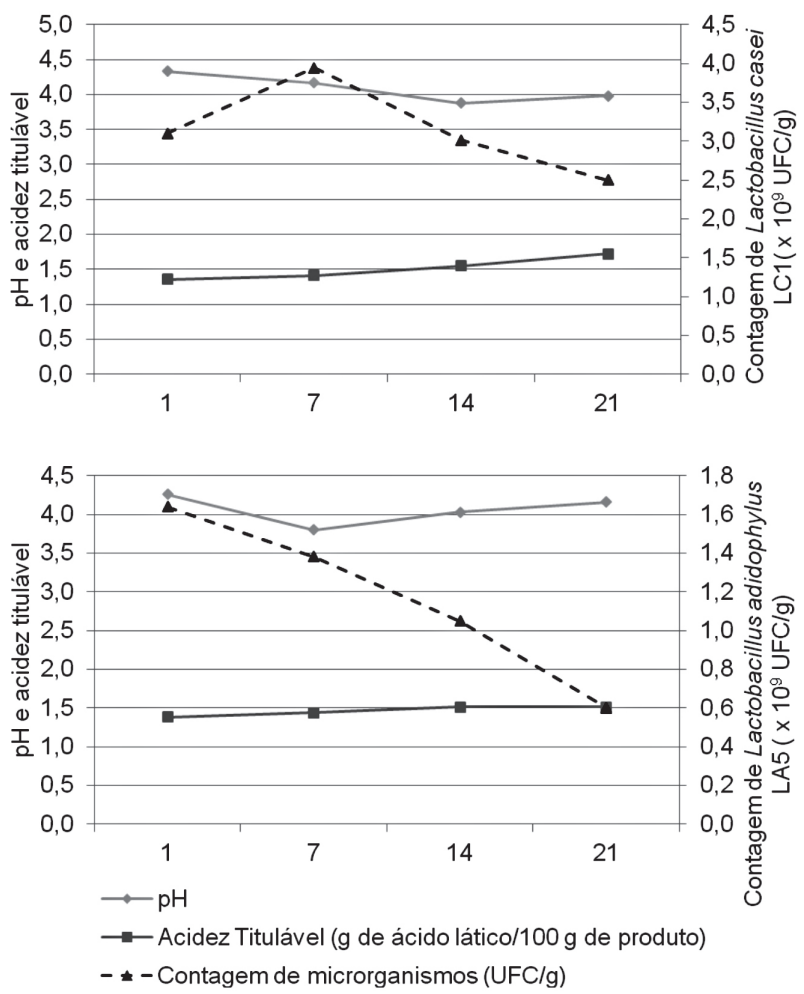

Figura 1 - Evolução dos parâmetros físico-químicos (pH e acidez titulável) e da contagem de microrganismos probióticos dos queijos tipo Quark $\mathrm{F}_{1}$ (Lactobacillus casei LC1) e $\mathrm{F}_{2}$ (Lactobacillus acidophilus LA5) durante armazenamento a $6{ }^{\circ} \mathrm{C}$ por 21 dias 
ao longo do armazenamento. No entanto, não foram observadas diferenças estatísticas ao longo do período de armazenamento $(p>0,05)$ entre os dois microrganismos. A Legislação Brasileira de compostos bioativos (ANVISA, 2002) determina que a quantidade mínima viável para os probióticos deve estar situada na faixa de $10^{8}$ a $10^{9}$ UFC na porção diária ou $10^{6}$ a $10^{7} \mathrm{UFC} / \mathrm{g}$ de produto.

A efetividade da ação dos lactobacilos como adjuntos na dieta humana é obtida por valores situados entre $10^{7}$ e $10^{9}$ células viáveis por ingestão diária. A estabilidade dos lactobacilos neste estudo superou os números encontrados na literatura para alimentos probióticos. Cardarelli et al. (2008) avaliaram a viabilidade de Lactobacillus acidophilus Lac4 em queijo Petit-suisse probiótico e obtiveram contagens de 1,2 a 9,7 x $10^{6} \mathrm{UFC} / \mathrm{g}$ após 28 dias de armazenamento sob refrigeração, valores inferiores aos observados no presente estudo.

Os valores médios de atividade de água foram de 0,986 para $\mathrm{F}_{1}$, fermentada por $L$. casei $\mathrm{LC} 1$, e 0,979 para $\mathrm{F}_{2}$, com L. acidophilus LA5. Como esperado para este tipo de produto, a atividade de água observada está acima dos valores seguros para que não haja crescimento de bactérias patógenas. No entanto, o $\mathrm{pH}$ ácido desses produtos é uma barreira ao desenvolvimento de patogênicos.

A determinação de coliformes totais, coliformes termotolerantes e $S$. aureus em ambas as formulações revelou ausência destes grupos microbianos, indicando tratamento térmico adequado e manutenção de condições higiênicas adequadas durante processamento e armazenamento do produto. Em alimentos com características de alta acidez, baixo pH e presença de bactérias lácticas, há inibição da deterioração microbiana devido a presença de antimicrobianos naturais (WAGNER; MOBERG, 1989), além das práticas adequadas desde o desenvolvimento até o armazenamento.

A Tabela 1 apresenta a composição centesimal dos queijos tipo Quark elaborados com $L$. casei LC1 e L. acidophilus LA5. Observou-se que a composição centesimal foi semelhante entre os dois produtos $(p>0,05)$, embora contendo diferentes prebióticos e probióticos. Al-Kadamany et al. (2003) determinaram valores de composição centesimal em queijo Quark semelhantes ao presente trabalho $(74,5 \%$ de umidade, $8,3 \%$ de proteínas e $1,2 \%$ de cinzas), com exceção do teor de lipídeos, pois no presente trabalho foi utilizado leite desnatado.

Tabela 1 - Composição centesimal dos queijos tipo Quark $\mathrm{F}_{1}$ (Lactobacillus casei LC1) e $\mathrm{F}_{2}$ (Lactobacillus acidophilus LA5)

\begin{tabular}{ccc}
\hline Composição $(\%)^{*}$ & Lactobacillus casei LC1 & Lactobacillus acidophilus LA5 \\
\hline Umidade & $67,99^{\mathrm{a}}$ & $68,46^{\mathrm{a}}$ \\
Extrato Seco Total & $32,01^{\mathrm{a}}$ & $31,54^{\mathrm{a}}$ \\
Proteínas & $8,17^{\mathrm{a}}$ & $8,13^{\mathrm{a}}$ \\
Lipídeos & $2,09^{\mathrm{a}}$ & $2,10^{\mathrm{a}}$ \\
Carboidratos** & $20,73^{\mathrm{a}}$ & $20,33^{\mathrm{a}}$ \\
Cinzas & $1,02^{\mathrm{a}}$ & $0,98^{\mathrm{a}}$ \\
\hline
\end{tabular}

* Valores médios de duas determinações.

** Carboidratos calculados por diferença.

Letras iguais sobrescritas na mesma linha indicam que não houve diferença significativa pelo teste t de Student $(\mathrm{p}>0,05)$. 
Os padrões legais para este tipo de queijo variam de um país para outro. $\mathrm{Na}$ Alemanha, queijo Quark deve apresentar mínimo de $18 \%$ de matéria seca e de $12 \%$ de proteínas, enquanto o Kwark holandês deve apresentar no máximo $87 \%$ de umidade e o mínimo de $60 \%$ de proteínas no extrato seco desengordurado (SCHULZ-COLLINS; SENGE, 2004). Segundo o Regulamento Técnico de Identidade e Qualidade de Queijos (BRASIL, 2000), o queijo Petit-suisse (que é semelhante ao Quark) é classificado como queijo de muita alta umidade, com teor de umidade não inferior a $55 \%$, e mínimo de $6 \%$ de proteínas lácteas. Considerando esses padrões, os produtos obtidos nas formulações $\mathrm{F}_{1}$ e $\mathrm{F}_{2}$ atendem aos requisitos de identidade e qualidade.

A quantificação de EPS foi realizada nos leites fermentados antes do processo de dessora, e apresentou valores médios de $103,5 \mathrm{mg} / 100 \mathrm{~g}$ e $109,2 \mathrm{mg} / 100 \mathrm{~g}$ para as formulações $\mathrm{F}_{1}-L$. casei LC1 e $\mathrm{F}_{2}-L$. acidophilus LA5, respectivamente. Pode-se observar que tanto $L$. casei LC1 quanto $L$. acidophilus LA5 produziram quantidades semelhantes de EPS $(p>0,05)$. Embora cada microrganismo tenha produzido na presença de prebiotico diferente (L. casei LC1 com goma acácia e L. acidophilus LA5 com inulina), ambos estavam sob condições otimizadas para a produção de EPS conforme combinação probiótico-prebiótico selecionada por Schiavão-Souza et al. (2007) para otimização da produção de EPS por bactérias láticas. A produção de EPS pode contribuir significativamente para desenvolvimento de textura, reologia, percepção de sabor e estabilidade do produto final. Além disso, EPS produzidos por bactérias láticas possuem alegação de capacidade prebiótica, antitumoral, antiúlcera, efeitos imunodulatórios (ALP; ASLIM, 2010) e também podem reduzir o colesterol sanguíneo (RUASMADIEDO, et al., 2001). Durlu-Ozkaya et al. (2007), estudando o efeito da produção de
EPS na resistência a bacteriófagos e nisina, verificaram que $L$. delbruekii subsp. bulgaricus B3 produziu a maior quantidade de EPS (315 mg/L). Esta alta produção foi correlacionada à maior resistência a bacteriófagos dessa linhagem. Segundo Alp; Aslim (2010), uma capa ou biofilme protetor de EPS ao redor das células pode permitir que a bactéria resista às condições de acidez e bile do trato gastrointestinal, além de maior aderência à mucosa e permitir um tempo de residência prolongado.

\section{CONCLUSÕES}

Para ambos os produtos com combinações probiótico-prebiótico ao longo de 21 dias de armazenamento a $6{ }^{\circ} \mathrm{C}$ houve variação nos parâmetros de acidez, $\mathrm{pH}$ e contagem de microrganismos, ocorrendo uma pós-acidificação. Houve semelhante produção de exopolissacarídeos pelas bactérias probióticas utilizadas para produção do queijo tipo Quark. Ao final do período de armazenamento, a contagem de probióticos Lactobacillus casei LC1 e Lactobacillus acidophilus LA5 manteve-se nos níveis recomendados pela legislação brasileira para a alegação de produto funcional contendo probióticos, e foram superiores aos encontrados em produtos similares.

\section{REFERÊNCIAS}

AGÊNCIA NACIONAL DE VIGILÂNCIA SANITÁRIA (ANVISA). Resolução RDC $\mathrm{n}^{\circ} 2$, de 07 de janeiro de 2002. Aprova o Regulamento Técnico de Substâncias Bioativas e probióticos isolados com alegação de Propriedade funcional e ou de Saúde. Diário Oficial da República Federativa do Brasil, Brasília, 9 jan. 2002.

AL-KADAMANY, E. et al. Estimation of shelf-life of concentrated yogurt by monitoring selected microbiological and 
physicochemical changes during storage. LWT - Food Science and Technology, v. 36, n. 4, p. 407-414, 2003.

ALP, G.; ASLIM, B. Relationship between the resistance to bile salts and low $\mathrm{pH}$ with exopolysaccharide (EPS) production of Bifidobacterium spp. isolated from infants feces and breast milk. Anaerobe, v. 16, n. 2, p. 101-105, 2010.

BRASIL. Ministério da Agricultura. Métodos analíticos oficiais para controle de produtos de origem animal e seus ingredientes: I Métodos microbiológicos e II Métodos físicoquímicos. Brasília: LANARA, 1981.

BRASIL. Ministério da Agricultura, Pecuária e Abastecimento. Instrução Normativa $n^{\circ}$ 53, de 29 de dezembro de 2000. Aprova o regulamento técnico de identidade e qualidade do queijo petit-suisse. Diário Oficial da República Federativa do Brasil, Brasília, 04 jan. 2001. Seção 1, p. 3

CARDARELLI, H. R. et al. Inulin and oligofructose improve sensory quality and increase the probiotic viable count in potentially synbiotic petit-suisse cheese. LWT - Food Science and Technology, v. 41, n. 6, p. 1037-1046, 2008.

CHAMPAGNE, C. P. et al. The potential of immobilized cell technology to produce freeze-dried, phage-protected cultures of Lactococcus lactis. Food Research International, v. 25, n. 6, p. 419-427, 1992.

DE VUYST, L. et al. Recent developments in the biosynthesis and applications of heteropolysaccharides from lactic acid bacteria. International Dairy Journal, v. 11, n. 9, p. 687-707, 2001.

DURLU-OZKAYA, F.; ASLIM, B.; OZKAYA, M. T. Effect of exopolysaccharides (EPSs) produced by Lactobacillus delbrueckii subsp. Bulgaricus strains to bacteriophage and nisin sensitivity of the bacteria. LWT - Food Science and Technology, v. 40, n. 3, p. 564568, 2007.

MARUYAMA, L. Y. et al. Textura instrumental de queijo petit-suisse potencialmente probiótico: influência de diferentes combinações de gomas. Ciência e Tecnologia de Alimentos, v. 26, n. 2, p. 386-393, 2006.

ROBERFROID, M. B. Functional Foods Concepts: The case of inulin and oligofructose. Journal of Nutrition, v. 129, n. 7, p. 1398S-1401S, 1999.

RUAS-MADIEDO, P. HUGENHOLTZ, J.; ZOON, P. An overview of the functionality of exopolysaccharides produced by lactic acid bacteria. International Dairy Journal, v. 12, n. 2-3, p. 163-171, 2001.

SCHIAVÃO-SOUZA, T. D. et al. Produção de Exopolissacarídeos por Bactérias Probióticas: Otimização do Meio de Cultura. Brazilian Journal of Food Technology, v. 10, n. 1, p. 27-34, 2007.

SCHULZ-COLLINS, D.; SENGE, B. Acid and Acid/Rennet-curd Cheeses. Part A: Quark, Cream Cheese and Related Varieties. In: FOX, P. F. et al. Cheese: chemistry, physics and microbiology. Oxford: Elsevier, 2004. 3 ed. v. 2, p. 301-328.

WAGNER, M. K.; MOBERG, L. J. Present and Future Use of Traditional Antimicrobials. Food Technology, v. 155, n. 1, p. 143-147, 1989.

ZIEMER, C.; GIBSON, G. An overview of probiotics, prebiotics and symbiotics in the functional concept: perspectives and future strategies. International Dairy Journal, v. 8, n. 5-6, p. 473-479, 1998. 